\title{
Social Functions in Autistic Children and Interaction with/through Object: A Brief Report
}

\author{
Giulia Savarese ${ }^{1 *}$, Federico Manzi ${ }^{2,3}$, Antonio Iannaccone ${ }^{3}$ \\ ${ }^{1}$ Department of Medicine and Surgery, University of Salerno, Baronissi (Sa), Italy \\ ${ }^{2}$ Department of Psychology, Research Unit on Theory of Mind, Università Cattolica del Sacro Cuore, Milan, Italy \\ ${ }^{3}$ Institut de Psychologie et Education, Université de Neuchâtel, Neuchâtel, Switzerland \\ Email: *gsavarese@unisa.it
}

How to cite this paper: Savarese, G., Manzi, F., \& Iannaccone, A. (2017). Social Functions in Autistic Children and Interaction with/through Object: A Brief Report. Psychology, 8, 1129-1133. https://doi.org/10.4236/psych.2017.88073

Received: April 29, 2017

Accepted: June 9, 2017

Published: June 12, 2017

Copyright @ 2017 by authors and Scientific Research Publishing Inc. This work is licensed under the Creative Commons Attribution International License (CC BY 4.0).

http://creativecommons.org/licenses/by/4.0/ cc) (i) Open Access

\begin{abstract}
The aim is to analyse the social functions of pointing, of imitation and of joint attention in presence of the object for the autistic children. We have built an ad-hoc observation check-list and we have conducted 43 observations with verbal ASD-affected children aged between 2 years and 6 years. The results show that a better use of the object is correlated to the manifestation of social functions analysed.
\end{abstract}

\section{Keywords}

Autistic Children, Objects, Social Functions

\section{Introduction}

In a socio-material perspective (Iannaccone, 2015), the object is composed of material features and social components coexisting together. Considering that the social interaction is impaired in autistic children; consequently, the interaction with the "social world of objects" is impaired as well (Iannaccone, at al., 2016).

Some autistic children show deficits in the use of objects: alterations in manipulation, exploration and describing. Thus, autistic children which do not present impairment in the use of the object show more social functions than impaired children (Trevarthen \& Hubley, 1978; Tomasello, 1995; 2016).

The three social functions, pointing, imitation and joint attention analysed in the study and they all have in common the presence of the object in their definition. Thus, our aim is to analyse these functions not only taking into account the development of these by the autistic child, but also what role plays the object 
specifically in social and relational terms.

\section{Method}

We have built an ad-hoc observation check-list inquiring on 9 areas (each of which has specifying under-questions), which refer to 9 psychological theory constructs developed by the literature on autism and object.

The main objective of this check-list is that of describing characteristics and socio-material functions of the object with reference to autistic subjects. In this check-list, there are different psychological constructs, but here we have analysed in detail three constructs: declarative function, imitation and attention. As we can see the check-list was made of different constructs but we will analyse these other constructs in future.

During each observation, an educator following the child for rehabilitation was present and the educator completed the check-list. Each observation lasted 26 minutes on average and has been transcribed on an ad-hoc check-list.

Children have been observed while interacting with an object, a small-sized plastic toy, they had chosen from a set of objects, for instance, toy cars, trains, toy animals and others.

When we refer to "acted and interacted with and through the object" we arranged different constructs of the check-list, such as: Understanding of the use of the object, interaction through the objects etc. Which are the constructs refer to the manipulation, exploration and describing.

We carried out 43 observations with verbal ASD-affected children aged between the end of the sensory-motor stage (24 months) and the start of the preoperational stage (68 months, namely 6 years). Moreover, the literature shows some results showing a link between a better use of the object and those functions that emerge during the pre-operating period, such as imitation and attention to the other (Bruckner \& Yoder, 2007).

We were two samples. The first sample composed of 18 children who acted and interacted with and through the object while the second sample composed of 25 children who acted and interacted with and through the object.

\section{Results}

Regarding the association between the sample 1 and the declarative function (Figure 1) shows that the $66.7 \%$ of the sample present this association while the sample 2 shows that only the $24 \%$ present this association.

Indeed, it is possible also for autistic children to use the imperative function of pointing, as for typical development children, and pointing is often the groundbreaking of a full declarative function (Camaioni et al., 2003).

Regarding the association between the sample 1 and the imitation (Figure 2) shows that the $94.4 \%$ of the sample present this association while the sample 2 shows that only the $60 \%$ present this association.

Concerning imitation, it has been suggested that the specific imitation deficit of autism could be reduced or even eliminated with the use of activities linked to 


\section{Pointing function}

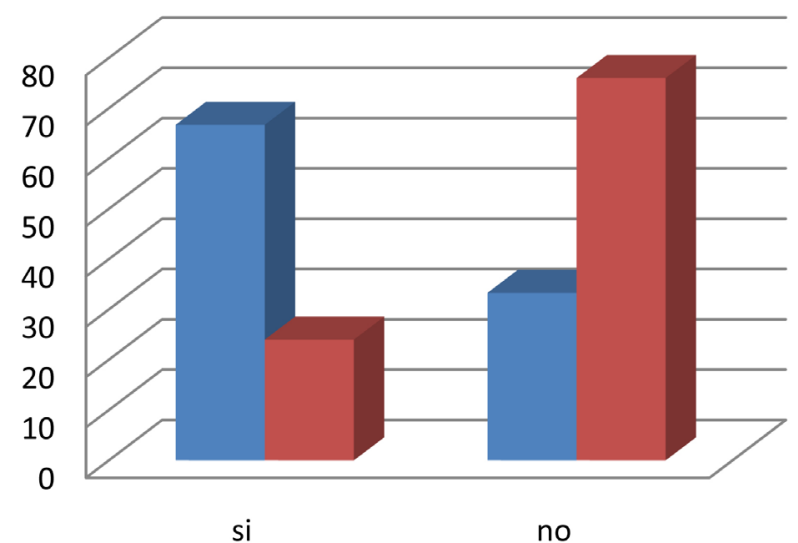

sample 1: action/interaction through the object

- sample 2: non action/interaction through the object

Figure 1. Pointing function.

\section{Imitation function}

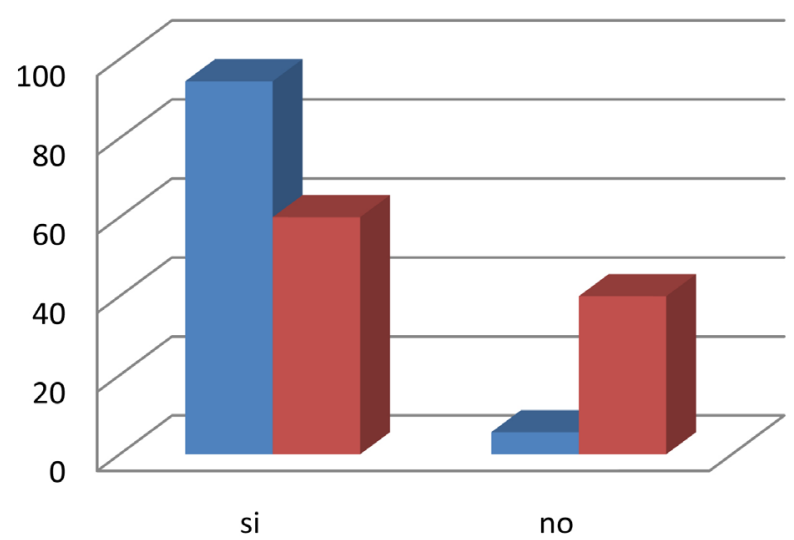

ample 1: action/interaction through the object

ample 2: non action/interaction through the object

Figure 2. Imitation function.

\section{Joint attention}

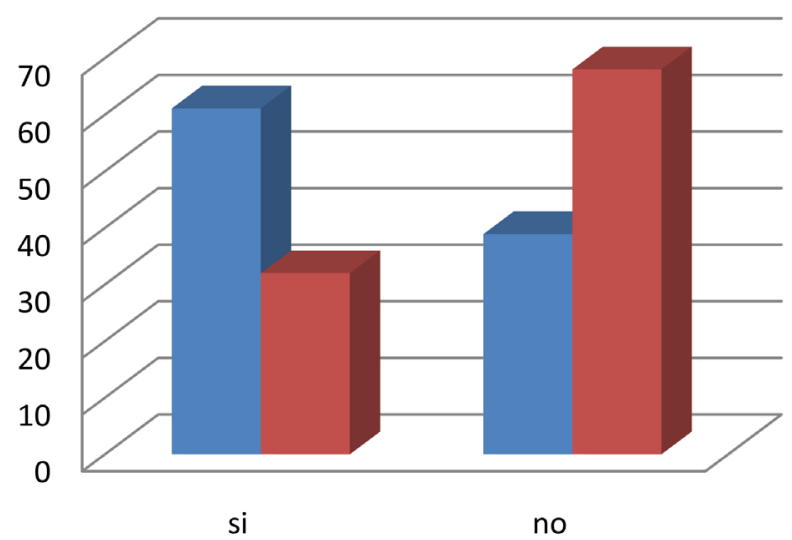

- sample 1: action/interaction through the object

ample 2: non action/interaction through the object

Figure 3. Attention to the adult function.

objects (Vanvuchelen et al., 2013; Custance et al., 2014), especially when no 
timelines in the use of objects are given. This would favour a higher joint attention, motor imitation and intentional communication with a social partner (Swettenham et al., 1998).

Regarding the association between the sample 1 and the Joint attention (Figure 3 ) shows that the $61.1 \%$ of the sample present this association while the sample 2 shows that only the $32 \%$ present this association.

Lastly, regarding joint attention it has been proved that manipulation of material objects can address the child's attention and favour the joint attention with both adults and peers (Korkiakangas \& Rae, 2013).

\section{Conclusion}

The socio-material features of the object represent factors that mediate the construction of the interaction with the adult. Social functions contribute to this process are: the declarative function (relating to pointing), the imitative function, the function of joint attention.

In line with the literature (Bruckner \& Yoder, 2007) on the child with typical development, our study with autistic children shows a link between a better use of the object and these functions that emerge during the pre-operating period, such as imitation and attention for interacting with people.

\section{References}

Bruckner, C. T., \& Yoder, P. (2007). Restricted Object Use in Young Children with Autism Definition and Construct Validity. Autism, 11, 161-171. https://doi.org/10.1177/1362361307075709

Camaioni, L., Perucchini, P., Muratori, F., Parrini, B., \& Cesari, A. (2003). The Communicative Use of Pointing in Autism: Developmental Profile and Factors Related to Change. European Psychiatry, 18, 6-12. https://doi.org/10.1016/S0924-9338(02)00013-5

Custance, D. M., Mayer, J. L., Kumar, E., Hill, E., \& Heaton, P. F. (2014). Do Children with Autism Re-Enact Object Movements Rather than Imitate Demonstrator Actions? Autism Research, 7, 28-39. https://doi.org/10.1002/aur.1328

Iannaccone, A. (2015). Materiality and Educational Psychology. Paper Presented at the Symposium "Materiality and Human Development". $16^{\text {th }}$ Meeting of the International Society for Theoretical Psychology, Coventry, 27-30 June 2015.

Iannaccone, A., Savarese, G., \& Manzi, F. (2016). The Use of Objects for Autistic Children: A Study in Piagetian Perspective and the Use of Construction Blocks. Poster Presented at the Conference: "XXIX Congresso Nazionale AIP-Sezione di Psicologia dello Sviluppo e dell’Educazione”, Vicenza, 8-10 September 2016.

Korkiakangas, T. K., \& Rae, J. P. (2013). Gearing up to a New Activity: How Teachers Use Object Adjustments to Manage the Attention of Children with Autism. Augmentative and Alternative Communication, 29, 83-103. https://doi.org/10.3109/07434618.2013.767488

Swettenham, J., Baron-Cohen, S., Charman, T., Cox, A., Baird, G., Drew, A., \& Wheelwright, S. (1998). The Frequency and Distribution of Spontaneous Attention Shifts between Social and Nonsocial Stimuli in Autistic, Typically Developing, and Nonautistic Developmentally Delayed Infants. Journal of Child Psychology and Psychiatry, 39, 747-753. https://doi.org/10.1017/S0021963098002595

Tomasello, M. (1995). Joint Attention as Social Cognition. In C. Moore, \& P. J. Dunham 
(Eds.), Joint Attention: Its Origins and Role in Development (pp. 103-130). Hillsdale, NJ: Lawrence Erlbaum Associates Inc.

Tomasello, M. (2016). Cultural Learning Redux. Child Development, 87, 643-653. https://doi.org/10.1111/cdev.12499

Trevarthen, C., \& Hubley, P. (1978). Secondary Intersubjectivity: Confidence, Confiding, and Acts of Meaning in the First Year. In J. Lock (Ed.), Action, Gesture and Symbol (pp. 183-229). London: Academic Press.

Vanvuchelen, M., Van Schuerbeeck, L., Roeyers, H., \& De Weerd, W. (2013). Understanding the Mechanisms behind Deficits in Imitation: Do Individuals with Autism Know "What" to Imitate and Do They Know "How" to Imitate? Research in Develop mental Disabilities, 34, 538-545.

Submit or recommend next manuscript to SCIRP and we will provide best service for you:

Accepting pre-submission inquiries through Email, Facebook, LinkedIn, Twitter, etc. A wide selection of journals (inclusive of 9 subjects, more than 200 journals)

Providing 24-hour high-quality service

User-friendly online submission system

Fair and swift peer-review system

Efficient typesetting and proofreading procedure

Display of the result of downloads and visits, as well as the number of cited articles

Maximum dissemination of your research work

Submit your manuscript at: http://papersubmission.scirp.org/

Or contact psych@scirp.org 